\title{
Peer influence on speeding behaviour among male drivers aged 18 and 28
}

\author{
Møller, Mette; Haustein, Sonja
}

Published in:

Accident Analysis \& Prevention

Link to article, DOI:

http://dx.doi.org/doi:10.1016/j.aap.2013.11.009

Publication date:

2014

Document Version

Publisher's PDF, also known as Version of record

Link back to DTU Orbit

Citation (APA):

Møller, M., \& Haustein, S. (2014). Peer influence on speeding behaviour among male drivers aged 18 and 28. Accident Analysis \& Prevention, 64, 92-99. https://doi.org/doi:10.1016/j.aap.2013.11.009

\section{General rights}

Copyright and moral rights for the publications made accessible in the public portal are retained by the authors and/or other copyright owners and it is a condition of accessing publications that users recognise and abide by the legal requirements associated with these rights.

- Users may download and print one copy of any publication from the public portal for the purpose of private study or research.

- You may not further distribute the material or use it for any profit-making activity or commercial gain

- You may freely distribute the URL identifying the publication in the public portal

If you believe that this document breaches copyright please contact us providing details, and we will remove access to the work immediately and investigate your claim. 


\title{
Peer influence on speeding behaviour among male drivers aged 18 and 28
}

\author{
Mette Møller*, Sonja Haustein \\ Technical University of Denmark (DTU), Department of Transport, Bygningstorvet 116B, DK-2800 Kgs. Lyngby, Denmark
}

\section{A R T I C L E I N F O}

\section{Article history:}

Received 13 August 2013

Received in revised form 14 October 2013

Accepted 18 November 2013

\section{Keywords:}

Young male drivers

Speeding

Subjective norm

Peer pressure

Attitudes

Traffic violations

\begin{abstract}
A B S T R A C T
Despite extensive research, preventive efforts and general improvements in road safety levels, the accident risk of young male drivers remains increased. Based on a standardized survey of a random sample of 2018 male drivers at the age of 18 and 28, this study looked into attitudes and behaviours related to traffic violations of male drivers. More specifically, the role of peer influence on speeding was examined in both age groups. In regression analyses it could be shown that the descriptive subjective norm, i.e., the perception of friends' speeding, was the most important predictor of speeding in both age groups. Other significant factors were: negative attitude towards speed limits, injunctive subjective norm, and the perceived risk of having an accident when speeding. In the older age group it was more common to drive faster than allowed and their speeding was largely in line with the perceived level of their friends' speeding. In the younger age group a higher discrepancy between own and friends' speeding was found indicating that young male drivers are socialized into increased speeding behaviour based on peer pressure. By contrast for the 28-year-olds peer pressure mainly seems to maintain or justify individual speeding behaviour. It is suggested that preventive measures should take these different influences of peer pressure into account by using a peer-based approach for the 18-year-olds and a more individual approach for the 28-year-olds.
\end{abstract}

(c) 2013 Elsevier Ltd. All rights reserved.

\section{Introduction}

Based on their persistence over time, some road safety problems appear to be more difficult to solve than others. As stated by Elvik (2010) the young driver problem is a clear case as the accident risk of young drivers, particularly young male drivers, remains increased despite extensive research and preventive efforts in the area as well as general improvements in road safety levels.

The large number of factors contributing to the young driver problem can be categorized in a number of different ways. A useful categorisation has been proposed by Gregersen and Bjurulf (1996) who distinguish between factors related to the process of learning to drive on the one side and motivational factors related to the individual preconditions and social influence on the other side.

Based on previous research it is clear that motivational factors are of particular relevance in relation to young male drivers as improvements in driving skills do not eliminate the gender difference in accident risk (Ferguson et al., 2007; Lam, 2003). In addition, it has been shown that the increased accident risk of young male drivers is partly a consequence of voluntary engagement in

\footnotetext{
* Corresponding author. Tel.: +45 45256500 .

E-mail address: mm@transport.dtu.dk (M. Møller).
}

high-risk behaviours and situations (Clarke et al., 2005; Özkan and Lajunen, 2006; Williams, 2003). Similarly, young male drivers have a more negative and less compliant attitude towards traffic rules and traffic safety compared to other drivers (Bergdahl, 2005; Laapotti et al., 2003; Kweon and Kockelman, 2006; Yagil, 1998), they perceive driving situations as less risky (Finn and Bragg, 1986; Tränkle et al., 1990), are more likely to disregard the speed limit (Cestac et al., 2011; Williams et al., 2006), and are influenced by a socialization process leading to stereotyped gender role identification which encourages risk-taking behaviour among male drivers (Özkan and Lajunen, 2006; Sibley and Harré, 2009). Finally, young male drivers have been shown to be involved in a proportionally higher number of accidents related to motivational factors compared to young female drivers (Laapotti and Keskinen, 2004).

According to Berkman (2000) social influence is a concept used to cover the effect others have on the attitudes and behaviour of individual persons and groups. In relation to driving behaviour the importance of motivational factors stemming from social influence was already identified many years ago (e.g., Zaidel, 1992). Since then results of a number of studies have highlighted the complex nature of social influence on young driver behaviour which can be categorized according to two interrelated dimensions: (1) direct versus indirect social influence, and (2) active versus passive social influence. 
The direct-indirect dimension regard social influence stemming from persons present in the car while driving versus social influence stemming from other road users present in the general traffic environment. Regarding passenger influence, results are ambiguous but indicate that the influence varies according to the relationship between the young driver and the passenger such as the passenger being the parent of the driver (e.g., Scott-Parker et al., 2012) or a peer (e.g., Simons-Morton et al., 2011; Johnson et al., 2012), as well as according to individual characteristics of the passenger such as age (e.g., Williams et al., 2007) and gender (e.g., Simons-Morton et al., 2005). Regarding social influence from road users present in the traffic environment, sources of influence include the perception of the actual behaviour of the other road users (e.g., Åberg et al., 1997; Haglund and Åberg, 2000) and perceived pressure to behave in a certain way such as keeping up with the traffic flow (e.g., Fleiter et al., 2010).

The active-passive dimension regard social influence stemming from verbal encouragement by passengers and passive influence such as perceived pressure or norms to behave in a certain way and anticipated punishments and rewards from parents and peers (e.g., Gregersen and Berg, 1994; Møller, 2004; Scott-Parker et al., 2009; Horvath et al., 2012). Previous research indicates that the influence from passive peer pressure is particularly strong (Sela-Shayovitz, 2008).

Due to the well-documented gender differences in road traffic accident risk and driving behaviour, exploring the influential factors separately for male and female drivers has been suggested as a relevant approach (e.g., Horvath et al., 2012; Møller and Haustein, 2013). Additional support for a gender specific approach is found in the fact that male drivers appear to be more susceptible to social influence than female drivers (e.g., Conner et al., 2003; Cestac et al., 2011). A possible explanation for this difference may be found in gender specific differences in peer group relationships with male relationships being more competitive and involving a higher level of risk compared to female relationships (Simon and Corbett, 1996).

The importance of peer influence on the behaviour of young drivers is generally acknowledged and integrated into preventive measures such as graduated licensing systems for instance through restrictions on number and age of passengers allowed (e.g., Williams and Shults, 2010; Fell et al., 2011; Williams et al., 2012). However, only limited knowledge on peer influence into early adulthood is available. On this basis the main purpose of the present study was to see if a similar relationship between driving behaviour and peer influence is present among male drivers at the age of 18 and 28. A particular focus is put on speeding as driving speed and speeding violations continue to be a major factor in relation to road safety (Aarts and van Schagen, 2006; Clarke et al., 2010; Elvik, 2010; Iversen and Rundmo, 2004).

The role of social influence on speeding has mostly been investigated within the framework of the Theory of Planned Behaviour (Ajzen, 1991), showing that self-reported speeding or the intention to speed can be successfully explained by attitude towards speeding, perceived social pressure to speed (=subjective norm) and perceived ability to speed (=perceived behavioural control) (e.g., Cestac et al., 2011; Conner et al., 2003; Elliott et al., 2005; Forward, 2009; Letirand and Delhomme, 2005; Warner and Åberg, 2006). Among other constructs, the inclusion of descriptive subjective norm, which measures beliefs about other people's speeding, significantly contributed to explaining variance in speeding intention (Cestac et al., 2011; Forward, 2009). In this study peer influence is measured by both injunctive and descriptive subjective norms and this study examined what role these factors play for speeding at the age of 18 and 28 besides other factors, such as socio-demographic, attitudinal and behavioural variables.

\section{Method}

\subsection{Data collection}

Data for the survey was collected by postal questionnaires using one reminder letter. The questionnaire consisted of a combination of questions used in a previous study on a related matter (see Møller and Gregersen, 2008) and questions developed specifically for this study based on a Danish study on social norms (see Balvig et al., 2005). The questionnaire included 51 questions. A stamped and addressed envelope was enclosed in all letters with the questionnaire. The sample consisted of 4000 male drivers randomly drawn from the Danish Driving Licence Register. The selection criteria ensured that all participants got their licence at the age of 18 and had the opportunity to achieve some driving experience after licensing. Thus half of the sample was 18-years-old with 6-12 months of driving experience. The other half was 28 -years-old with between 10 years and 6 months and 11 years of driving experience. The overall response rate was $51 \%(N=2018)$. The response rate among the 18 -year-olds was $53 \%(N=1055)$. The response rate among the 28 -year-olds was $48 \%(N=963)$.

\subsection{Measures}

The questionnaire used included background information, driving behaviour including traffic violations, subjective norms and attitudes and beliefs towards traffic rules and behaviours as well as parts which are not relevant for this study.

Background information included education, occupation, having children, and residential area.

Driving behaviour: The frequency of driving was measured on a four point scale ranging from $1=$ " $4-7$ days per week" to 4 = "less than 1 day per month". Participants were further asked on a 5point scale ranging from $1=$ "always" to $5=$ "never" how often they exceeded the speed limit, when there was a possibility to do so. The assessment was made separately for driving in built-up areas and on rural roads. On the same scale the frequency of driving without a safety belt was assessed both on highways and within built-up areas. Drivers were further asked how often they (ever and within the past 12 months) had driven under the influence of alcohol (1= "never"; 2 = "one time"; 3 = "a few times"; $4=$ "several times"). Finally, they were asked if they had (ever and within the past 6 months) been involved in an accident and if they had (ever and within the past 6 months) been ticketed for different violations of the traffic rules (speeding, driving without a safety belt, drunk driving).

Peer influence: Peer influence was measured by two constructs: descriptive and injunctive subjective norm (SN). Participants were asked how often they expected their best friends to drive at excessive speed in built-up areas and on rural roads (from 1 = "always" to $5=$ "never"), which is referred to as descriptive $S N$. In addition they were asked how they expected their best friends to react in five different situations, violating the traffic rules (see Fig. 2 for a list of items), which is referred to as injunctive $S N$. The drivers could answer that friends would either "approve" (1) of the participant's behaviour, would "not care" (2) or would "try to prevent" (3) the respective behaviour.

Attitudes towards traffic rules and behaviours. Participants were asked to assess 12 statements expressing different attitudes about speeding, the use of safety belts, drunk driving, and general behaviour in traffic (see Fig. 1 for a list of all items). A factor analysis with varimax rotation was conducted based on the 12 items and revealed a four-factor solution explaining $53.3 \%$ of the variance. Based on a factor related to attitudes towards speed limits a mean scale was constructed (Cronbach's alpha $=.63$ ), which was 


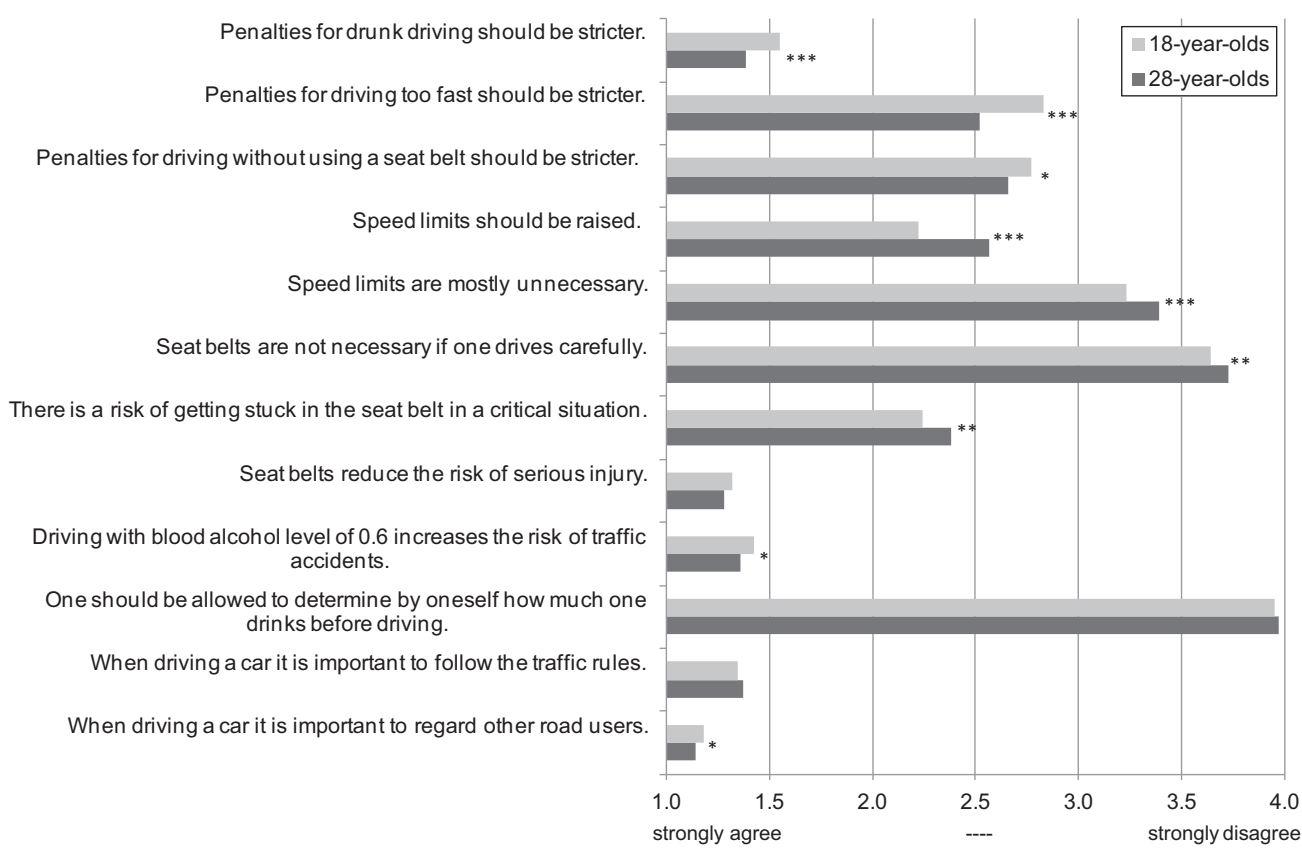

Fig. 1. Attitudes towards traffic rules and violations. Note: Mean differences between younger and older road users tested in $t$-tests: ${ }^{*} p<.05$; ${ }^{* *} p<.01 ;{ }^{* * *} p<.001$.

used in a regression analysis to predict driving at excessive speed (see Section 3.4).

In addition, the drivers were asked to assess the accident risk when driving: (a) $70 \mathrm{~km} / \mathrm{h}$ in built-up areas (speed limit $=50 \mathrm{~km} / \mathrm{h}$ ) and (b) $100 \mathrm{~km} / \mathrm{h}$ on a rural road ( ppeed limit $=80 \mathrm{~km} / \mathrm{h}$ ). The assessment was made on a 5-point scale ranging from 1 = "very high" to 5 = "very low".

\subsection{Statistical analysis}

To test whether 18- and 28-year-old drivers differed significantly from each other with regard to driving behaviour, traffic violations and related attitudes and norms, Pearson's $\chi^{2}$ test, Mann-Whitney $U$-test and $t$-test were used, as appropriate.

A linear regression analysis was conducted to analyze which variables predicted driving at excessive speed. We used a simultaneous regression model as we had no basis for considering any variable to be prior to any other. As predictors, socio-demographic and behavioural variables were used, as well as attitudes and subjective norms.

\subsection{Respondents}

Most of the respondents in the sub-sample of 18-year olddrivers ( $87.4 \%$ ) were still in education ( $27 \%$ on a technical school, on a $26 \%$ gymnasium; $16 \%$ on a business school), while $80.4 \%$ of the 28-year-old had finished education. Most of them had completed technical school (24.1\%), business school (12.0\%), a bachelor $(12.5 \%)$ or master degree $(11.4 \%)$. While almost none of the young drivers (.6\%) had children yet, a third $(32.9 \%)$ of the older age group were parents. The 18-years-olds were rather equally distributed between living in rural areas (26.5\%), small towns (33.7\%), suburban areas (19.3\%), and big cities (20.6\%), whereas the older participants lived predominantly in big cities (49.7\%).

These differences will be controlled for in the regression analysis predicted driving at excessive speed (see Section 3.4).

\section{Results}

\subsection{Driving behaviour and fines for traffic offences}

As the results in Table 1 show 28-year-olds drove more often on a regular basis. While for 28 -year-olds it was more probable that they ever had an accident and ever drove under the influence of alcohol, it was less probable for them that they did this in the recent past than it was for the novice drivers. By contrast, the 18-year-olds used a safety belt more often than the older drivers did.

Regarding fines for offending the traffic rules, 28-year-olds naturally received a fine more often than 18 -years-old, simply because of the longer driving history. Tickets for speeding were most common among the 28-year-olds with more than half of them ever having received one. Generally, driving without a safety belt and especially drunk driving were less often fined. Although about 70\% of the 28-year-olds admitted to have ever driven under the influence of alcohol, less than $3 \%$ had ever gotten a fine. If only the past 6 months are considered, 28-year-olds received a ticket for speeding more often than 18-year-olds. The differences for other offences were not significant.

\subsection{Attitudes towards traffic rules and violations}

Fig. 1 shows how the 18- and 28-year-old drivers assessed 12 statements regarding different traffic rules and behaviours. Generally, it was strongly agreed that one should follow the traffic rules and consider other road users. Also both age groups acknowledged the risk of driving while drunk and almost no one thought that it should be up to the individual driver to determine how much to drink before driving. Similarly, using a seat belt was strongly accepted as a means to reduce the risk of serious injury and seat belts were regarded as necessary - even when driving carefully. Still, the risk of getting stuck in the seat belt in a critical situation was partly agreed to. While stricter penalties for drunk driving would be accepted, especially by the older age group, the acceptance of stricter penalties for driving too fast and without a safety belt was much lower, especially with regard to the 
Table 1

Driving behaviour and fines for traffic offences.

\begin{tabular}{|c|c|c|c|}
\hline & $\begin{array}{l}\text { Percentage within } \\
\text { 18-year-olds }\end{array}$ & $\begin{array}{l}\text { Percentage within } \\
\text { 28-year-olds }\end{array}$ & $\begin{array}{l}\text { Test for difference between age } \\
\text { groups: } U \text {-test } / \chi^{2} \text {-test results }\end{array}$ \\
\hline Driving 4-7 days per week & 68.5 & 79.3 & $U=461,569.5 ; p<.001$ \\
\hline Drunk driving at any time & 33.7 & 71.8 & $U=333,510.0 ; p<.001$ \\
\hline Drunk driving within the past 12 months & 34.2 & 17.5 & $U=407,992.5 ; p<.001$ \\
\hline Accident at any time & 13.2 & 46.3 & $\chi^{2}(1, N=1993)=264.3, p<.001$ \\
\hline Accident within the past 6 months & 9.0 & 2.6 & $\chi^{2}(1, N=1990)=36.3, p<.001$ \\
\hline Seldom/never use safety belt on highways & 2.9 & 5.1 & $U=467,341.5 ; p<.001$ \\
\hline Seldom/never use safety belt in built-up areas & 5.1 & 9.7 & $U=431,692.0 ; p<.001$ \\
\hline Ticket for speeding at any time & 6.9 & 54.0 & $\chi^{2}(1, N=1991)=530.2, p<.001$ \\
\hline Ticket for speeding within the past 6 months & 6.0 & 9.9 & $\chi^{2}(1, N=1988)=10.8, p<.01$ \\
\hline Ticket for driving w/o safety belt at any time & 3.5 & 14.4 & $\chi^{2}(1, N=1991)=75.5, p<.001$ \\
\hline Ticket for driving w/o safety belt within the past 6 months & 2.5 & 1.6 & $\chi^{2}(1, N=1988)=2.0, p=.15$ \\
\hline Ticket for drunk driving at any time & .2 & 2.7 & $\chi^{2}(1, N=1991)=23.3, p<.001$ \\
\hline Ticket for drunk driving within the past 6 months & .1 & .1 & $\chi^{2}(1, N=1988)=.0, p=.95$ \\
\hline
\end{tabular}

younger group of drivers. More younger than older drivers thought that speed limits were mostly unnecessary and should be raised, even though the majority of both groups regarded speed limits as necessary.

There was no significant difference in the perceived accident risk when driving too fast between the younger and older age group, neither for the risk perception in built-up areas, nor on rural roads ( $t$-tests, $p>.10)$. Generally, the accident risk when driving too fast in built-up areas was perceived as "big" $(M=2.1)$ while the risk on rural roads was perceived as neither big nor small $(M=2.9)$.

\subsection{Peer influence}

\subsubsection{Injunctive subjective norm}

As Fig. 2 shows most drivers expected their friends to accept it when they drove too fast. Younger drivers speeding on rural roads expected the highest approval. Also for driving without a safety belt only about 25\% expected their friends to intervene (both age groups). The picture looks very different for drunk and drug driving. Here, around 90\% expected their friends to try to prevent the respective behaviour; again the younger group showed higher approval.

\subsubsection{Descriptive subjective norm}

Drivers were asked how often they thought their friends would drive at excessive speed within the city and on rural roads (descriptive SN). In Fig. 3 the means for both age groups are presented and compared with the drivers' own speeding behaviour. There were three main findings: Firstly, speed limits on rural roads were more often violated than those in built-up areas. Secondly, the older age group (admitted to) exceed the speed limits more often than the younger age group, and finally, there was a higher discrepancy between drivers' own speeding behaviour and the respective descriptive norm in the younger age group, especially on rural roads, where 28-year-olds own behaviour and expected friends' behaviour were almost the same.

\subsection{Explaining driving at excessive speed}

To examine the relative effect of different factors on speeding, a linear regression analysis was conducted. For this analysis all items that were measured separately for the situation in builtup areas and on rural roads were merged to cross-situational mean scales, which was possible because of acceptable internal consistencies (Cronbach's alpha between .69 and .71). Driving at

What do you think, how would your friends react...

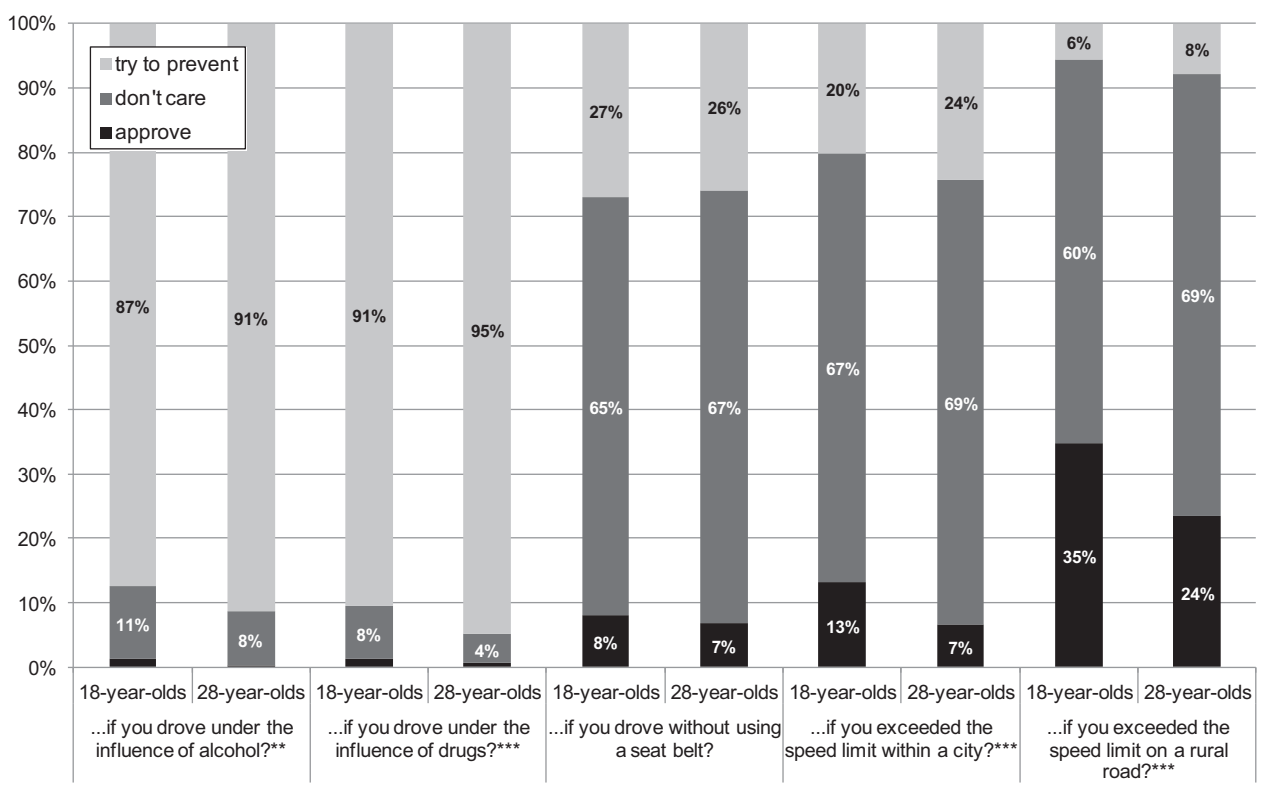

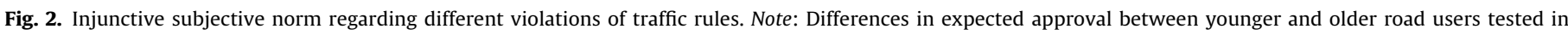
Mann-Whitney $U$-test: ${ }^{* *} p<.01 ;{ }^{* * *} p<.001$. 


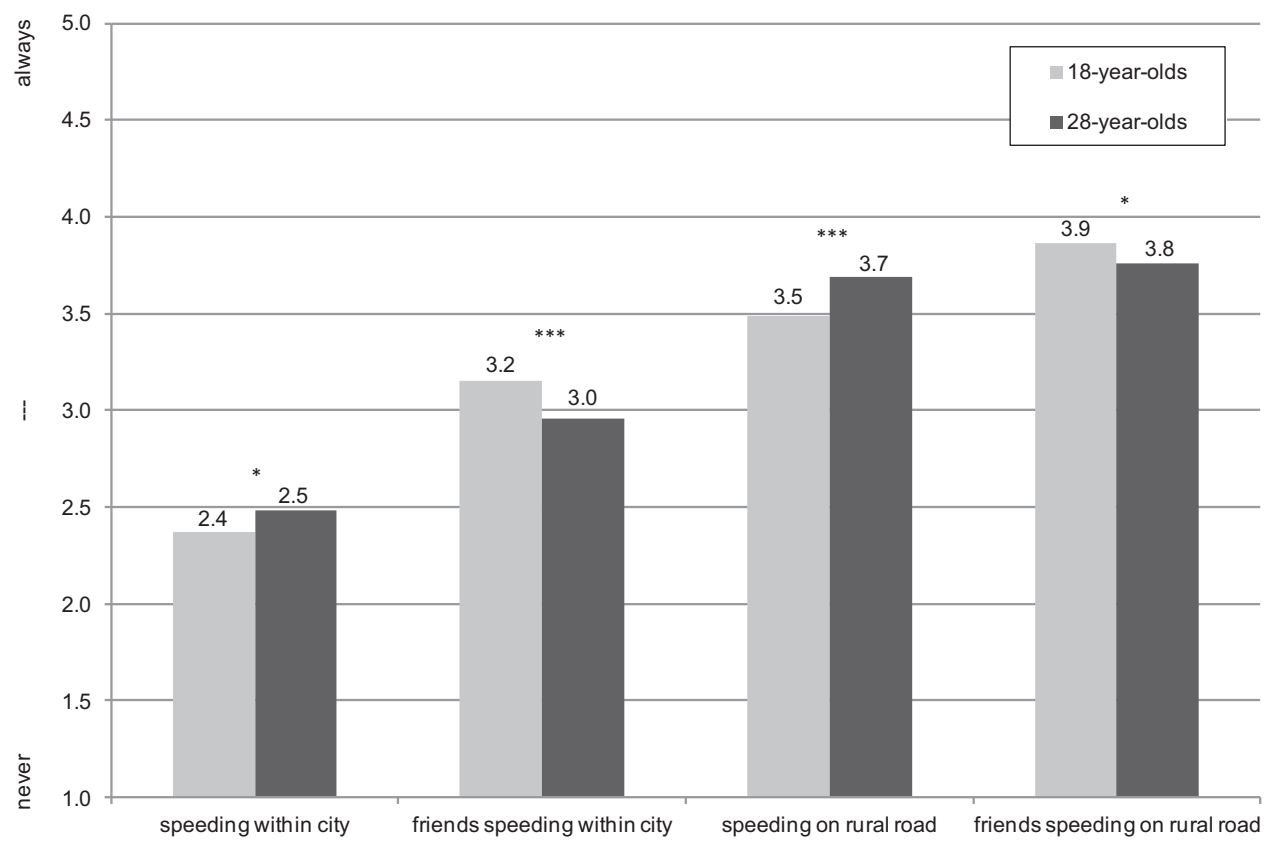

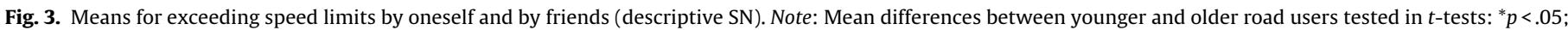
$*^{* * *} p<.001$

excessive speed was predicted by the socio-demographic variables education, having children, and residential area. Further, driving frequency, previous accident involvement and being ticketed for speeding were included. As attitudinal variables the attitude towards speed limits were included as well as the perceived accident risk when driving too fast. Further, expectations about friends' reaction towards own driving at excessive speed (injunctive SN) and about how often friends drove too fast (descriptive SN) were entered.

Altogether three linear regression analyses were conducted, one for the whole sample and one for each age group separately (see Table 2), explaining between $47 \%$ and $49 \%$ of the variance in speeding. The regression for the whole sample contained one additional predictor, which was the age group, showing that older drivers reported that they more often drove too fast than younger drivers. Having children had a significant influence on the older age group (almost no one in the younger group had children yet), indicating that being a father either reduced speeding or that those who drove too fast were less likely to have children (at that age). People who drove more frequently reported driving faster than allowed more often than people who drove less frequently. While previous accident involvement was not related to speeding, having received a ticket for speeding was related to reported speeding behaviour. Having received a ticket, however, did not have a preventive effect on speeding, but just indicated that those, who more often drove too fast, also got a ticket more often. By far the most important predictor was the assessment, how often friends drove too fast. All other psychological variables were also significant but of lower relevance.

Comparing the results of the two different age groups, the results showed substantial similarities. In each regression the same predictor became significant, except for the age-related variables (having children, and ever having received a ticket for speeding). However, there were some smaller differences in the relative importance of the psychological variables. While for both age groups descriptive SN was most important, injunctive SN had a higher influence on younger drivers, as well as attitudes regarding speed limits. In contrast, for older drivers the perceived accident risk was of higher relevance for speeding.

\section{Discussion}

In this study the role of peer influence on speeding was examined in male drivers aged 18 and 28. Speeding was more accepted than drunk driving and was found to be more common in the older group compared to the younger group. In both groups the most important predictor of speeding was the perception of the speeding behaviour of their friends. However, the results indicate that social norms influence behaviour differently at the age of 18 and 28 and that young male drivers are socialized into increased speeding based on peer pressure.

The descriptive results regarding traffic violations and respective attitudes are generally consistent with previous literature. In line with other studies (Cauzard, 2004; Cestac and Delhomme, 2012; Iversen and Rundmo, 2004) the disapproval of drunk driving was generally higher than the disapproval of other traffic violations. Still, about $70 \%$ of the 28 -year-olds and one third of the 18 -year-olds admitted to driving under the influence of alcohol at some point. Considering the increased accident risk related to drunk driving (Gjerde et al., 2011; Hels et al., 2013; Taylor et al., 2010) preventive efforts targeting drunk driving are thus still highly relevant. A particular focus should be put on young drivers as drunk driving was found to be more common in the younger age group. Lifestyle factors (Gregersen and Berg, 1994; Begg et al., 1999) as well as parental influences (Leadbeater et al., 2008) have previously been shown to be of importance for drunk driving among young drivers. Preventive measures aimed at the parents are thus of key importance. Such measures should aim to ensure that parents serve as appropriate role models and that they make arrangements to prevent their children from drunk driving in relation to parties or the like.

While drunk driving was more common in the group of younger drivers, speeding was more common in the older age group. This finding is supported by previous research indicating that speeding increases with age (Elvik, 2010; Cestac et al., 2011). Nevertheless, the attitude towards speed limits was more negative among the 18 -year-olds than among the 28 -year-olds. Similar results have been found in previous studies showing that young drivers perceive traffic laws as less important than older drivers (e.g., Iversen and Rundmo, 2004; Yagil, 1998). Based on existing knowledge, this age 
Table 2

Simultaneous linear regression analysis predicting excessive driving.

\begin{tabular}{|c|c|c|c|c|c|c|c|c|c|}
\hline & \multicolumn{3}{|l|}{ All } & \multicolumn{3}{|c|}{ 18-Year-olds } & \multicolumn{3}{|c|}{ 28-Year-olds } \\
\hline & $B$ & SE $B$ & $\beta$ & $B$ & SE $B$ & $\beta$ & $B$ & SE $B$ & $\beta$ \\
\hline (Constant) & 2.24 & .19 & $* * *$ & 2.50 & .29 & **** & 2.24 & .24 & **** \\
\hline 18 - versus 28 -year-olds & .31 & .04 & $.17^{* * *}$ & & & & & & \\
\hline Only basic education & .00 & .05 & .00 & .00 & .08 & .00 & -.02 & .08 & -.01 \\
\hline Children & -.10 & .05 & $-.04^{*}$ & .32 & .30 & .03 & -.11 & .04 & $-.06^{*}$ \\
\hline Living in rural areas (1) versus big city (4) & .00 & .01 & .00 & -.02 & .02 & -.02 & .01 & .02 & .02 \\
\hline Car use frequency & .10 & .02 & $.07^{* * *}$ & .12 & .04 & $.07^{* *}$ & .08 & .03 & $.07^{* * *}$ \\
\hline Accident at any time & .01 & .04 & .01 & .01 & .07 & .00 & .02 & .04 & .01 \\
\hline Ticket for speeding & .08 & .04 & $.04^{*}$ & .02 & .09 & .00 & .12 & .04 & $.07^{* *}$ \\
\hline Attitude: pro speed limits & -.20 & .02 & $-.17^{* * *}$ & -.26 & .04 & $-.19^{* * *}$ & -.15 & .03 & $-.14^{* * *}$ \\
\hline Descriptive SN & .53 & .02 & $.48^{* * *}$ & .51 & .03 & $.46^{* * *}$ & .55 & .03 & $.50^{* * *}$ \\
\hline Injunctive SN & -.27 & .04 & $-.14^{* * *}$ & -.34 & .05 & $-.17^{* * *}$ & -.20 & .05 & $-.11^{* * *}$ \\
\hline Perceived accident risk & -.16 & .02 & $-.14^{* * *}$ & -.15 & .03 & $-.12^{* * *}$ & -.17 & .03 & $-.17^{* * *}$ \\
\hline$R^{2}$ & & & .476 & & & .467 & & & .491 \\
\hline $\operatorname{adj} . R^{2}$ & & & .473 & & & .462 & & & .486 \\
\hline
\end{tabular}

Predictors were checked for multicollinearity: variance inflation factors (VIF) of all variables were below 2 .

${ }^{* *} p<.01$.

**** $p<.001$.

difference can be explained by at least two factors: firstly, young people may perceive speed limits in opposition to age-related motivation for individual freedom and independence (Laapotti et al., 2001; Møller and Gregersen, 2008). Secondly, speed limits may be perceived as interfering with thrill seeking and showing off while driving, which has previously been shown to be a characteristic element in the driving behaviour of young male drivers (Gregersen and Berg, 1994; Bina et al., 2006; Machin and Sankey, 2008; Møller and Haustein, 2013).

In a regression analysis, speeding could successfully be explained by a negative attitude towards speed limits, descriptive $\mathrm{SN}$, injunctive $\mathrm{SN}$, and the perceived risk of having an accident when speeding. For both age groups descriptive subjective norm, referring to the expectation that friends drive faster than allowed, was by far the most important predictor. This result is so far remarkable as social conformity has generally been found to decrease with age from early adolescence into early adulthood (e.g., Steinberg, 2004; Sumter et al., 2009; Walker and Andrade, 1996). However, the results also show that injunctive subjective norm has a slightly higher importance for the younger age group. This indicates that even though peers influence driving behaviour at both ages, they influence it differently at the age of 18 and 28 .

Speeding behaviour of the 28-year-old drivers was generally in line with their perception of social norms among friends indicated by similar reported levels in their own and expected friends' speeding behaviour. This suggests that at the age of 28 indirect passive peer pressure serves to maintain or justify individual speeding behaviour. In contrast, a larger discrepancy was found between perceived social norms and the behaviour of 18-year-old drivers, which may cause a higher perceived pressure to engage in speeding behaviour. Thus the results indicate that indirect passive peer pressure may influence young male drivers to speed more than they actually want to. Due to age related factors such as lifestyle (Gregersen and Berg, 1994; Møller and Sigurðardóttir, 2009), general level of maturity (Reyna and Farley, 2006) and limited driving experience they may end up speeding in high risk situations that they are unable to handle and end up in speeding related crashes. The more experienced drivers (the 28-year olds) may choose more "suitable" speeding situations, which would explain why they less often end up in speeding related accidents despite speeding more often. Thus, the results of this study suggest that even though young male drivers start out by speeding to a lesser degree they are being socialized into increased speeding behaviour based on peer pressure as well as pressure from the actual speeding of other road users.
This study is based on self-reported data. Such data has previously been shown to be reliable (Hatakka et al., 1997; Lajunen and Summala, 2003). Never the less with regard to self-report of traffic accidents and violations a possible effect of social desirability (Lajunen et al., 1997) should be taken into account. To overcome social desirability bias in this study confidentiality and anonymity was assured. In addition a neutral phrasing of the questions was applied as recommended by Hatakka et al. (1997). In addition the use of postal questionnaires allowed the respondents to fill out the questionnaire in privacy. Alternatively, information about traffic violations and accidents could have been based on data registered by the police. However, as indicated by previous studies (e.g., Arthus et al., 2001; Ye and Lord, 2011) many accidents and violations remain undetected and unreported causing underreporting bias. A comparison of the self-reported fines with the police registered fines at the individual level, could have uncovered possible bias in the data. However, such comparison was not possible within the limits of this study.

To achieve representative samples of male drivers of both age groups, two random samples were drawn from the Danish Driving Licence Register. With $51 \%$ an acceptable response rate was achieved. Response rates in both samples were comparable, indicating that possible non-response effects are about the same in both groups and do not influence the comparison of the groups.

With regard to non-response a general distinction between cognitive and motivational reasons can be made (Abrahamson and Abrahamson, 1999). The cognitive reasons refer to aspects such as difficulties in reading and writing, whereas a motivational reason could be a lack of interest in the subject of the study. Generally, the respondents indicated a high frequency of driving. Therefore, it is possible that non-responders drove less frequently and therefore did not find it relevant to participate in the study. However, as the specific reasons for non-response in this study are unknown this suggestion cannot be verified. Based on results from an earlier study (West and Hall, 1997) it is unlikely that non-response is influenced by previous accident history. However, it is unknown if this is also the case in relation to violations. Due to the unknown reasons for non-response self-selection bias is possible. However, as participation is voluntary, such bias is difficult to eliminate completely.

\section{Implications}

The results indicate that in order to prevent speeding and speeding related crashes in the future peer influence has to be taken 
into account. However, results also indicate that peers influence behaviour differently according to age. Consequently, peer influence should be addressed differently at different ages.

At the age of 18 the injunctive subjective norm and thus their expectations regarding friends' reaction to speeding was of particular importance. In terms of preventive efforts this has two implications. Firstly, it emphasises the relevance of peer based preventive measures. This is supported by studies showing a positive effect of preventive measures such as the Norwegian "speak out" campaign in which young people were encouraged to prevent risk-taking behaviour among peers by explicitly expressing their disapproval of such behaviour (Elvik, 2000). Secondly, it underlines the relevance of measures that support non-speeding behaviour by correcting misperceptions regarding speeding behaviour among peers. Support for this is found in studies on other risk-taking behaviours (e.g., Perkins and Berkowitz, 1986; Balvig et al., 2005). However, to address such misperceptions in an appropriate way, it is crucial to know to what extend their perceptions regarding the driving behaviour of peers are in accordance with actual peer behaviour. Unfortunately, this study does not allow such clarification. Therefore, before initiating preventive measures a relevant next step would be to clarify the extent of misperceptions among young male drivers. Such clarification would be relevant not only in relation to speeding behaviour but also in relation to other problem behaviours among young drivers.

Regarding the 28-year-old drivers the results of the study indicate that a different approach than the approach suggested for the 18-year-olds is needed. Based on the consistency between self-reported speeding and perceived speeding among peers social norms seem to justify or maintain speeding behaviour among the 28-year-old male drivers. Therefore, in order to prevent speeding a relevant strategy could be to address each driver individually and to encourage him to stand out and behave responsibly not only for his own sake but also to serve as a good role model for the sake of increased road safety.

\section{Conclusion}

The main purpose of this study was to see if a similar relationship between driving behaviour and peer influence is present among male drivers at the age of 18 and 28 with a particular focus on speeding. The results show that the perception of peer behaviour influences own behaviour at both ages. However, the type of influence varies according to age. Thus at the age of 18 peer influence leads to increased speeding behaviour where as it serves to maintain and justify speeding behaviour at the age of 28 . Future efforts to prevent speeding behaviour should take the age specific influence of peer influence into account. Such efforts would benefit from a clarification of the relationship between perceived and actual behaviour of peers at different ages.

\section{References}

Aarts, L., van Schagen, I., 2006. Driving speed and the risk of road crashes: a review. Accident Analysis and Prevention 38, 215-224.

Abrahamson, J.H., Abrahamson, Z.H., 1999. Survey Methods in Community Medicine: Epidemiological Research, Programme Evaluation, Clinical Trials, 5th ed. Churchill Livingstone, Edinburgh.

Ajzen, I., 1991. The theory of planned behavior. Organizational Behavior and Human Decision Processes 50, 179-211.

Arthus, W., Tubre, T., Day, E.A., Sheehan, M.K., Sanchez-Ku, M.L., Paul, D., Paulus, L., Archuleta, K., 2001. Motor vehicle crash involvement and moving violations: convergence of self-report and archival data. Human Factors 43, 1-11.

Åberg, L., Larsen, L., Glad, A., Beilisson, L., 1997. Observed vehicle speed and drivers' perceived speed of others. Applied Psychology: An International Review 46, 287-302.

Balvig, F., Holmberg, L., Sørensen, S.A., 2005. Ringstedforsøget: Livsstil og forebyggelse i lokalsamfundet. DJøF.
Begg, D.J., Langley, J.D., Williams, S.M., 1999. A longitudinal study of lifestyle factors as predictors of injuries and crashes among young adults. Accident Analysis and Prevention 31, 1-11.

Bergdahl, J., 2005. Sex differences in attitudes toward driving: a survey. The Social Science Journal 42, 595-601.

Berkman, L.F., 2000. Social support, social networks, social cohesion and health Social Work in Health Care 31, 3-14

Bina, M., Graziano, F., Bonino, S., 2006. Risky driving and lifestyles in adolescence Accident Analysis and Prevention 38, 472-481.

Cauzard, J.P. (Ed.), 2004. European Drivers and Road Risk. SARTRE 3 Report, Part 1. Institut National de Recherche sur les Transports et leur Sécurité (INRETS).

Cestac, J., Delhomme, P. (Eds.), 2012. European Road Users' Risk Perception and Mobility. The SARTRE 4 Survey. SARTRE Consortium.

Cestac, J., Paran, F., Delhomme, P., 2011. Young drivers' sensation seeking, subjective norms, and perceived behavioural control and their roles in predicting speeding intention: how risk-taking motivations evolve with gender and driving experience. Safety Science 49, 424-432.

Clarke, D.D., Ward, P., Bartle, C., Truman, W., 2010. Killer crashes: fatal road traffic accidents in the UK. Accident Analysis and Prevention 42, 764-770.

Clarke, D.D., Ward, P., Truman, W., 2005. Voluntary risk taking and skill deficits in young driver accidents in the UK. Accident Analysis and Prevention 37, 523-529.

Conner, M., Smith, N., McMillan, B., 2003. Examining normative pressure in the theory of planned behaviour: impact of gender and passengers on intentions to break the speed limit. Current Psychology: Developmental, Learning, Personality, Social 22, 252-263.

Elliott, M.A., Armitage, C.J., Baughan, C.J., 2005. Exploring the beliefs underpinning drivers' intentions to comply with speed limits. Transportation Research Part F 8, 459-479.

Elvik, R., 2000. Evaluating the effectiveness of Norway's “Speak Out!” road safety campaign. The logic of causal inference in road safety evaluation studies. Transportation Research Record 1717, 66-75.

Elvik, R., 2010. Why some safety problems are more difficult to solve than others. Accident Analysis and Prevention 42, 1089-1096.

Fell, J.C., Todd, M., Voas, R.B., 2011. A national evaluation of the nighttime and passenger restriction components of graduated driver licensing. Journal of Safety Research 42, 283-290.

Ferguson, A.S., Teoh, E.R., McCartt, A.T., 2007. Progress in teenage crash risk during the last decade. Journal of Safety Research 38, 137-145.

Finn, P., Bragg, B.W.E., 1986. Perception of the risk of an accident by young and older drivers. Accident Analysis and Prevention 18, 289-298.

Fleiter, J.J., Lennon, A., Watson, B., 2010. How do other people influence your driving speed? Exploring the 'who' and the 'how' of social influences on speeding from a qualitative perspective. Transportation Research Part F 13, 49-62.

Forward, S.E., 2009. The theory of planned behaviour: the role of descriptive norms and past behaviour in the prediction of drivers' intentions to violate. Transportation Research Part F 12, 198-207.

Gjerde, H., Normann, P.T., Christophersen, A.S., Samuelsen, S.O., Mørland, J., 2011. Alcohol, psychoactive drugs and fatal road traffic accidents in Norway: a case-control study. Accident Analysis and Prevention 43, 1197-1203.

Gregersen, N.P., Berg, H.Y., 1994. Lifestyle and accidents among young drivers. Accident Analysis and Prevention 26, 297-303.

Gregersen, N.P., Bjurulf, P., 1996. Young novice drivers: towards a model of their accident involvement. Accident Analysis and Prevention 28, 229-241.

Haglund, M., Åberg, L., 2000. Speed choice in relation to speed limit and influences from other drivers. Transportation Research Part F 3, 39-51.

Hatakka, M., Keskinen, E., Katila, A., Laapotti, S., 1997. Self-reported driving habits are valid predictors o violations and accidents. In: Rothengatter, T., Carbonell Vaya, E. (Eds.), Traffic and Transport Psychology. Theory and Application. Pergamon, Oxford, pp. 295-303.

Hels, T., Lyckegaard, A., Simonsen, K.W., Steentoft, A., Bernhoft, I.M., 2013. Risk of severe driver injury by driving with psychoactive substances. Accident Analysis and Prevention 59, 346-356.

Horvath, C., Lewis, I., Watson, B., 2012. The beliefs which motivate young male and female drivers to speed: a comparison of low and high intenders. Accident Analysis and Prevention 45, 334-341.

Iversen, H., Rundmo, T., 2004. Attitudes towards traffic safety, driving behaviour and accident involvement among the Norwegian public. Ergonomics 47 (5) 555-572.

Johnson, M.B., Voas, R.B., Miller, B.A., 2012. Driving decisions when leaving electronic music dance events: driver, passenger, and group effects. Traffic Injury Prevention 13, 577-584.

Kweon, Y.-J., Kockelman, K.M., 2006. Driver attitudes and choices: speed limits, seat belt use, and drinking-and-driving. Journal of the Transportation Research Forum 45, 39-56.

Laapotti, S., Keskinen, E., 2004. Has the difference in accident patterns between male and female drivers changed between 1984 and 2000. Accident Analysis and Prevention 36, 577-584.

Laapotti, S., Keskinen, E., Hatakka, M., Katila, A., 2001. Novice drivers' accidents and violations-a failure on higher or lower hierarchical levels of driving behaviour. Accident Analysis and Prevention 33, 759-769.

Laapotti, S., Keskinen, E., Rajalin, S., 2003. Comparison of young male and female drivers' attitude and self-reported traffic behaviour in Finland in 1978 and 2001. Journal of Safety Research 34, 579-587.

Lajunen, T., Carry, A., Summala, H., Hartley, L., 1997. Impression management and self-deception in traffic behaviour inventories. Personality and Individual Differences 22, 341-353. 
Lajunen, T., Summala, H., 2003. Can we trust self-reports of driving? Effects of impression management on driver behaviour questionnaire responses. Transportation Research Part F 6, 97-107.

Lam, L., 2003. Factors associated with young drivers' car crash injury: comparisons among learner, provisional, and full licensees. Accident Analysis and Prevention 35, 913-920.

Leadbeater, B.J., Foran, K., Grove-White, A., 2008. How much can you rink before driving? The influence of riding with impaired adults and peers on the driving behaviors of urban and rural youth. Addiction 103, 629-637.

Letirand, F., Delhomme, P., 2005. Speed behaviour as a choice between observing and exceeding the speed limit. Transportation Research Part F 8, 481-492.

Machin, M.A., Sankey, K.S., 2008. Relationship between young drivers' personality characteristics, risk perceptions, and driving behaviour. Accident Analysis and Prevention 40, 541-547.

Møller, M., 2004. An explorative study of the relationship between lifestyle and driving behavior among young drivers. Accident Analysis and Prevention 36, 1081-1088.

Møller, M., Gregersen, N.P., 2008. Psychosocial function of driving as predictor of risk-taking behaviour. Accident Analysis and Prevention 40, 209-215.

Møller, M., Haustein, S., 2013. Keep on cruising: changes in lifestyle and driving style among male drivers between the age of 18 and 23. Transportation Research Part F 20, 59-69.

Møller, M., Sigurðardóttir, S.B., 2009. The relationship between leisure time and driving style in two groups of male drivers. Transportation Research Part F 12, 462-469.

Özkan, T., Lajunen, T., 2006. What causes the differences in driving between young men and women? The effects of gender roles and sex on young driver's driving behavior and self-assessment. Transportation Research Part F 9, 269-277.

Perkins, H.W., Berkowitz, A.D., 1986. Perceiving the community norms of alcohol use among students: some research implications for campus alcohol education programming. International Journal of Addictions 21, 961-976.

Reyna, V.F., Farley, F., 2006. Risk and rationality in adolescent decision making: implications for theory, practice and public policy. Psychological Science in the Public Interest 7, 1-44.

Scott-Parker, B., Watson, B., King, M.J., 2009. Understanding the psychosocial factors influencing the risky behaviour of young drivers. Transportation Research Part F 12, 470-482.

Scott-Parker, B., Watson, B., King, M.J., Hyde, M.K., 2012. “They're lunatics on the road": exploring the normative influences of parents, friends, and police on young novices' risky driving decisions. Safety Science 50, 1917-1928.

Sela-Shayovitz, R., 2008. Young drivers' perceptions of peer pressure, driving under the influence of alcohol and drugs, and involvement in road accidents. Criminal Justice Studies: A Critical Journal of Crime, Law and Society 21, 3-14.

Sibley, C.G., Harré, N., 2009. A gender role socialization model of explicit and implicit biases in driving self-enhancement. Transportation Research Part F 12, 452-461.
Simon, F., Corbett, C., 1996. Road traffic offending, stress, age, and accident history among male and female drivers. Ergonomics 39, 757-780.

Simons-Morton, B., Lerner, N., Singer, J., 2005. The observed effects of teenage passengers on the risky driving behavior of teenage drivers. Accident Analysis and Prevention 37, 973-982.

Simons-Morton, B.G., Ouimet, M.C., Zhang, Z., Klauer, S.E., Lee, S.E., Wang, J., Chen, R., Albert, P., Dingus, T.A., 2011. The effect of passengers and risk-taking friends on risky driving and crashes/near crashes among novice teenagers. Journal of Adolescent Health 49, 587-593.

Steinberg, L., 2004. Risk taking in adolescence. What changes, and why? Annals New York Academy of Science 1021, 51-58.

Sumter, S.R., Bokhorst, C.L., Steinberg, L., Westerberg, P.M., 2009. The developmental pattern of resistance to peer influence in adolescence: will the teenager ever be able to resist? Journal of Adolescence 32, 1009-1021.

Taylor, B., Irving, H.M., Kanteres, F., Room, R., Borges, G., Cherpitel, C., Greenfield, T., Rehm, J., 2010. The more you drink, the harder you fall: a systematic review and meta-analysis of how acute alcohol consumption and injury or collision risk increase together. Drug and Alcohol Dependence 110, 108-116.

Tränkle, U., Gelau, C., Metker, T., 1990. Risk perception and age-specific accidents of young drivers. Accident Analysis and Prevention 22, 119-125.

Walker, M.B., Andrade, M.G., 1996. Conformity in the Asch task as a function of age. Journal of Social Psychology 136, 367-372.

Warner, H.W., Åberg, L., 2006. Drivers' decision to speed: a study inspired by the theory of planned behaviour. Transportation Research Part F 9, 427-433.

West, R., Hall, J., 1997. The role of personality and attitudes in traffic accident research. Applied Psychology: An International Review 46, 253-264.

Williams, A.F., 2003. Teenage drivers: patterns of risk. Journal of Safety Research 34, $5-15$.

Williams, A.F., Ferguson, S.A., McCartt, A.T., 2007. Passenger effects on teenage driving and opportunities for reducing the risks of such travel. Journal of Safety Research 38, 381-390.

Williams, A.F., Kyrychenko, S.V., Retting, R.A., 2006. Characteristics of speeders. Journal of Safety Research 37, 227-232.

Williams, A.F., Shults, R.A., 2010. Graduated driver licensing research, 2007-present: a review and commentary. Journal of Safety Research 41, 77-84.

Williams, A.F., Tefft, B.C., Grabowski, J.G., 2012. Graduated driver licensing research, 2010-present. Journal of Safety Research 43, 195-203.

Yagil, D., 1998. Gender and age-related differences in attitudes toward traffic laws and traffic violations. Transportation Research Part F 1, 123-135.

Ye, F., Lord, D., 2011. Investigation of effects of underreporting crash data on three commonly used traffic crash severity models. Multinomial logit, ordered probit, and mixed logit. Transportation Research Record 2241, 51-58.

Zaidel, D., 1992. A modeling perspective on the culture of driving. Accident Analysis and Prevention 24, 585-597. 